\title{
Enlightenment of Applying Central Plains Traditional Culture to Animation Industry Development
}

\author{
Hui Li \\ School of Arts and Design \\ Huanghe Science and Technology College \\ Zhengzhou, Henan, China 450063
}

\begin{abstract}
This article summarizes and sorts out diversified elements of Chinese traditional culture from multiple outstanding Chinese animation works, and following the clue of the practical application of Central Plains traditional cultural elements in animation making, explores the approach of realizing nationalization and localization for the new cultural industry - animation.
\end{abstract}

Keywords-Central Plains traditional culture; animation; original; inherit

\section{INTRODUCTION}

As a symbol of emerging cultural industry, animation has been attached with much attention and value by Henan province and it exists not only as a special art, but in a cultural form, so a successful anime role is more than just succeeding in animation art, also indicates great cultural value. As the shared understanding among animation enterprises, Henan has a bright prospect in animation industry, and such a populous province also fosters a large number of animation audiences. With the strong support and high value of provincial Party committee, provincial government, relevant departments and bureaus, it has established successively Henan Comics industry Association and Henan Animation Base; howsoever, comparing with other provinces and cities, Henan animation industry staggered its way to development and is seemingly short of power, so Henan still lags behind others in animation promotion. On the other hand, Central Plains Traditional Culture has experienced a long-term development to an entire set of characteristic cultural system; thus, to strengthen guidance on growth and focus on Central Plains features has become the inexorable trend of developing Central Plains animation industry through the application of traditional culture and fusion with amine making in suitable ways.

\section{MisundERSTANDING OF APPLICATION OF CENTRAL Plains TRADitional CULTURAL ElEMENTS}

\section{A. Immoderate Reliance on Native Subjects}

Blindly pursuing Chinese characteristics, Chinese animations are always telling traditional stories, for example, Havoc in Heaven, Nezha Conquers the Dragon King and Magic Lotus Lantern are all derived from myths or folklores and by now, those clichés still occupy a large part in Chinese cartoons. Since such classics have been quite familiar to people by books, televisions and games etc., no suspense remains for audiences even if performing as an animation. On the contrary, cliché and dull themes strip away the last energy of domestic anime movies along with the last attraction and imagination of audiences.

\section{B. Slavish Copy of American, Japanese and Korean Cartoon Culture}

5,000 thousand years of Central Plains traditional culture has accumulated lots of spirits worth of persistence and preciousness, especially under the time background of globalization, American, Japanese and Korean animations are widely sought after, and they are more than occupying anime market, further to cause a cultural colonization to our country by gradually exerting a subtle influence on audiences with carried value ideas and spirits.

At present, domestic animations, on account of utmost catering to the tastes of audiences, have lost Chinese characteristics and been branded with incomplete epitome or pathetic imitation of American or Japanese cartoons. For example, Magic Lotus Lantern and Nezha Conquers the Dragon King, despite of the good reputation as relatively preeminent works among a mass of China-made cartoons, still fail to dispense with the shadow of "little hero + lovely pet" the typical cartoon mode of Disney; especially the Magic Lotus Lantern, has faced with such a dilemma when building character images, that intends to both carry on Chinese style and cook Western style, so that it appears to be nondescript. Take the little stone monkey as example, its setting, character and images all follow Mushu in Hua Mulan and Smokie in Pocahontas. Besides, Gemei is also styled under obvious Americanization.

\section{C. "Educationism" and Restriction of "Shape"}

Throughout the whole Chinese history, arts always serve education to realize edutainment. However, the overstressed edutainment occurring in the cartoon making of contemporary China brings excessive cartoons themed by pedagogical meaning or science popularization and with poor quality and crude picture effects; neither plot arrangement of story, exertion of visual elements nor film language are really concerned by movie makers, but reasoning becomes the exclusive and paramount thing for a cartoon. If expecting China to have a share of global animation market, the concept 
of making cartoons has to be completely changed. Animations should be a stage to perform human hearts and can only deeply touch people when integrating more humanistic cares. At present, Chinese animation makers have started their journey in learning from western scriptwriters to utilize the movie language to tell stories; whereas, they still have a long way to go since there are lots of loopholes in multiple cartoons played in cinema. For instance, the cartoon Magic Lotus Lantern shapes relatively little roles with single characters. Excessive single-line links among characters leave no much expansion space of personality.

\section{Mechanical Application of Visual and Aural Elements of Central Plains Traditional Culture}

The broad and profound Central Plains traditional culture contains exceedingly rich traditional artistic forms, such as paper-cut, shadow puppet, Chinese ink painting, clay sculpture as well as traditional Chinese opera and folk music etc., and those national visual and aural elements have provided abundant resources for the nationalization of animation creations. To reveal national characters and realize nationalization by creating and spreading animation works, the artistic expressions are significant carriers, and most of modern anime works originate from traditional literatures, which, indeed, to some degree, can cover the shortage of scenario and is more likely to be accepted by audiences by picking up wellknown stories at random. Nonetheless, parts of movies just indiscriminately imitate classical stories with almost no changes, and are more seemed to disguise with the cover of mature classical stories and show off the advanced animation technology. It is not only the mechanical utilization of visual and audio elements of traditional culture but misunderstanding the essential of Chinese animation nationalization as rigid symbolization. However, for instance nobody would call a foreigner as a Chinese even if he dresses the imperial robe and speaks Chinese, the improper recognition implying incomprehensive viewpoint on an animation work from the perspective of both pattern of manifestation and ideological content, will isolate the uniformity between the artistic forms and contents during the nationalization of artistic creation.

\section{Styles AND ELEMENTS TO Highlight CENTRAL Plains TRADitional CUlture}

\section{A. Explore the Modern Value of Classic Native Themes}

$\mathrm{Lu}$ Xun once said "strictly selecting materials, deeply digging connotations" only by which, the overall level of works can be improved. Although lots of themes and subjects are applicable for making Chinese cartoons, it is definitely indispensable to conduct surveys on themes and audience demands. Animation, as a unique formative art, just like all other visual arts, not only requires its creator to familiarly grasp the means of artistic expression, artistic forms and connotations, but needs the feedback from audiences for further improvement. In conclusion, the first step to select materials is to appropriately sort out and summarize demands of audiences.

It is considered that traditional culture is thickly coated with intense color of this-worldly ideas and utilitarianism and lack of romance and imagination, and the reason why domestic cartoons are barely attractive is because it has greatly influenced by native culture and thoughts. To prosper the native animation, it must spring forth from the set pattern of quoting traditional culture and boldly learn the western animation experience. At the same time of those splendid artistic traditions suffering frequent negligence and abandonment under some domestic claims, America, Japan and other animation countries are frequently borrowing Chinese classical stories without compensation and have made many masterpieces, for example, Japanese animation starts from the 1950s with its first work that derives from one of the four Chinese famous legends Madam White Snake. Foreign cartoon talents have gradually discovered the charm of Chinese traditional culture and constantly gained inspiration from lively stories of our country; Japan rushes to register the trademark of Zhongan classical masterpieces, and has created no less than 30 kinds of Sanguo series games; for another, the US has presented some well-known Chinese stories including Generals of Yang Family, the Journey to the West and Angel Matches etc. on the stage, and the cartoon Hua Mulan derived from Mulan Ballad has become one of the new-generation anime classicals, in addition to Kung $F u$ Panda in which a plenty of Chinese cultural elements are exerted as well. In fact, our traditional culture is precious wealth for promoting the domestic animation industry and required supports of developing cultural industries in the new era. Considering from telling Chinese story to Chinese people in Chinesecharacterized tone, traditional cultural resources are suitable for spreading positive value; however, call a Spade a Spade, some animation works performing and derived from traditional culture cannot cast tremendous spell as expected because it fails to creatively take full use of those resources.

Take Zhuxian Town New Year pictures as example, it is quite worth of exploration to launch researches on combining the inheritance of Zhuxian Town New Year pictures and development of animation industry, which can remedy the shortage of native cultural reflection in Chinese animation development at the same time of protecting and rescuing intangible cultural heritages. For instance, applying the concise features of Zhuxian Town New Year pictures and remaining its plain character shape neither complying with routine nor proportion, as well as referring to its image elements such as gay colors and powerful thick lines, it is possible to express it in animation design as a symbol of Central Plains folk culture.

\section{B. Increase the Selection of Story Themes and Diversification of Structure Arrangement}

In order to satisfy different audiences, Japan adopts movie rating system and selects multi-element materials. The deduce theme represented by Detective Conan, tenderness subject on the behalf of Spirited Away, youth and sports story led by Slamdunk, magic and battle works represented by Inuyasha, historic culture themes stood for by The Annals of San Guo etc. have been accepted and appraised by different audiences. With regard to selection of materials, Japanese animations are succeeding in catering for the appetites of audiences and cover various fields oriented to audiences in different ages, jobs and educational backgrounds. American cartoons, despite of not so 
abundant categories as Japanese cartoons, lay particular stress on the manufacture of long-time cartoon films, and be able to appropriately serve audiences in diversified ages. On the contrary, Chinese cartoons either neglect the demands of audiences or are solely oriented to children, which is obviously harmful to the animation development. Nowadays, the ubiquitous animation has become an indispensable part of mass culture, and as an independent artistic form, should not be limited by the audiences' ages. Otherwise, it will be difficult to meet the demands of Chinese audiences even animation works sharply increasing in the market that is mainly occupied by American and Japanese cartoons.

Those unreal stories and characters that may happen in real life and also exist in imagination should be selected during role shaping, and it requires skillfully grasping the boundaries between imaginations and realities to reflect the ideological level that is rooted in life but bigger than life and create a virtual reality by seeking the essential truth from "untruthfulness" instead of being frozen by bygones. Moreover, to absorb the essence of pasts to nourish and motivate the current development and to select themes more fitting to the age is, above all, important to Chinese animation creation based on the critical explanation of Chinese traditional culture.

\section{Expand the Scope and Standard of Theme}

Some foreign countries earlier start their development in the animation industry and have shaped relatively mature technology. In addition, those countries have paid much attention to the excavation of whatever essence of traditional cultural resources of various countries. For example, Kong Fu Panda manufactured in America, costs five years of the director Mark Osborne who previously has been studying on Chinese culture for over 30 years. By shaping its main character "Po" - a witness of referring on Chinese cultural design of Mark, in addition to originally Chinese-characteristic scene design and American-style actions, the movie eventually succeeds and gains a high box office value. Besides, the Japanese animation Spirited Away was so popular to the world by virtue of absorbing the modeling features of Chinese traditional folk arts, especially the essence of New Year folk pictures, and further to add exaggerated transformation and overthrow the traditional modeling.

According to the Russian poet Pushkin, "Real national character is not about Russian ladies clothes, but to express the spirit of the people, and even when a poet describes a total stranger's world, still he will see it with eyes containing national elements. If the poet can speak loud on what his compatriots think, he would be possibly full of national characters." The deep excavation of native culture mostly depends on cultural deposits of creators; therefore, creators should have acute perspectives to its native culture.

\section{CONCLUSION}

Laying emphasis on the inheritance of traditional culture of Central Plains is aimed to provide more services for emerging animation culture; also, mirroring traditions is for serving the cultural life of modern people. It will hardly separate from the traditional and mature stylistic features under the belief that the transmission of traditions is equal to indiscriminately imitating grotto mural paintings, drama and paper-cut etc., which will lead to rest complacently on the laurels and be unable to extricate from the problem. Those animation works not fitting to its age cannot show the vitality and has no value of existence even with beautiful shapes; thus, the essay is expected to be of guiding significance to build up national brands of Chinese animation arts by discussing the enlightenment of applying the traditional culture of Central Plains to the development of animation industry. Let us jointly expect a bright future for Henan animation industry and the formation of animation arts with the characteristics of traditional culture of Central Plains, and finally erect status among international cartoon arts. We are expecting Chinese cartoon creates another peak.

\section{REFERENCES}

[1] [USA] Robert. C. Christopher. The Spirit of Japanese. Translated by Ma Quan \& Sun Jianlong, Guangming Daily Press, 1988.6

[2] Wu Guanying. Animation Artistic Design. Higher Education Press, 2001

[3] Wu Guangying. Animation Modeling Design. Tsinghua University Press, 2003

[4] Peng Ling. Introduction to Animation. Shanghai Jiaotong University Press, 2007.8

[5] H.S. Commager. The Spirit of American. Guangming Daily Press, 1988

[6] Chen Qijia. An Introduction to Japanese Animation Art. Shanghai Jiaotong University Press, 2006.3

[7] Xue Feng, Zhao Keheng \& Yu Fang. Cartoon Development History. Southeast University Press, 2006

[8] Feng Wen, Sun Lijun. An Introduction to Animation Art. Maritime Press, 2007

[9] Peng Jixiang. Introduction to Art. Peking University Press, 1994. 